\title{
Serum uric acid: an independent predictive marker for coronary artery disease
}

\author{
Erdim Sertoglu ${ }^{1}$
}

Received: 16 February 2015 / Accepted: 9 March 2015 / Published online: 22 March 2015

(C) International League of Associations for Rheumatology (ILAR) 2015

\section{Dear Editor,}

I read with great interest the recently published article by Dai et al. in which the authors aimed to explore the epidemiological association between serum uric acid (SUA) levels and cardiovascular involvements in a young Chinese population [1]. They concluded that SUA level higher than $8 \mathrm{mg} / \mathrm{dl}$ is a significant independent risk factor for the prevalence of cardiac structural and functional change in Chinese early-onset coronary artery disease (CAD) patients and suggested that higher SUA levels may play an important role in the pathophysiological process of cardiovascular dysfunction in coronary atherosclerosis. However, I think that there are some points that should be emphasized about this study.

First, it is stated that exclusion criteria included serious kidney disease (chronic kidney disease stages 4-5), in the original study. On the other hand, patients with diabetes and hypertension were included, as presented in Table 1 of [1]. However, because uric acid is predominantly cleared by the kidneys, a decline in glomerular filtration rate (GFR) will almost universally be associated with increased SUA [2]. Therefore, it would be better to exclude patients with these comorbidities, considering diabetes and hypertension as key risk factors for kidney disease. If still be included, it should be better to include only patients with preserved kidney function

Dr. Sertoglu holds an M.D. degree at Ankara Mevki Military Hospital.

Erdim Sertoglu

erdimsertoglu@gmail.com

1 Anittepe Dispensary, Biochemistry Laboratory, Ankara Mevki Military Hospital, Ankara, Turkey (estimated GFR $\geq 60 \mathrm{ml} / \mathrm{min} / 1.73 \mathrm{~m}^{2}$ ) which means with patients with stage $3 \mathrm{CKD}$ should also be excluded [3].

Second, although hyperuricemia was defined as SUA $\geq 7 \mathrm{mg} / \mathrm{dl}$ in men or $\geq 6 \mathrm{mg} / \mathrm{dl}$ in women, it was stated that all subjects were categorized into uric acid quartiles: first group (SUA $\leq 6 \mathrm{mg} / \mathrm{dl}$ ), second group $(6 \mathrm{mg} / \mathrm{dl}<\mathrm{SUA} \leq 7 \mathrm{mg} / \mathrm{dl}$ ), third group $(7 \mathrm{mg} / \mathrm{dl}<\mathrm{SUA} \leq 8 \mathrm{mg} / \mathrm{dl})$, and fourth group (SUA $>8 \mathrm{mg} / \mathrm{dl}$ ) in the original study. This means the second group is consisting of normouricemic men and hyperuricemic women. This may cause bias and may lead to misinterpretation of results possibly based on hyperuricemia, in comparing patient groups. Therefore, it would be more appropriate to perform receiver-operating characteristic analysis to determine the most appropriate cut-off values for both genders with hyperuricemia.

In conclusion, it is hard to understand if increased SUA is an independent predictive marker for CAD progression or developes as a result of a renal failure probably secondary to comorbidities associated with CKD.

Conflict of interest/financial disclosure statement The author states that there is no conflict of interests regarding the publication of this paper. This paper received no specific grant from any funding agency in the public, commercial, or not-for-profit sectors.

\section{References}

1. Dai XM, Wei L, Ma LL et al. (2015) Serum uric acid and its relationship with cardiovascular risk profile in Chinese patients with early-onset coronary artery disease. Clin Rheumatol

2. Marangella M (2005) Uric acid elimination in the urine. Pathophysiological implications. Contrib Nephrol 147:132-148

3. Kim WJ, Kim SS, Bae MJ et al (2014) High-normal serum uric acid predicts the development of chronic kidney disease in patients with type 2 diabetes mellitus and preserved kidney function. J Diabetes Complications 28:130-134 